DOE $/$ BETC/RI-81/2

Distribution Category UC-92b

\title{
DESIGN AND TESTING OF A PROCEDURE FOR EVALUATING FUEL-EFFICIENT CRANKCASE LUBRICANTS
}

By

Ted M. Naman

Bartlesville Energy Technology Center Bartlesville, Oklahoma

Date Published-April 1981

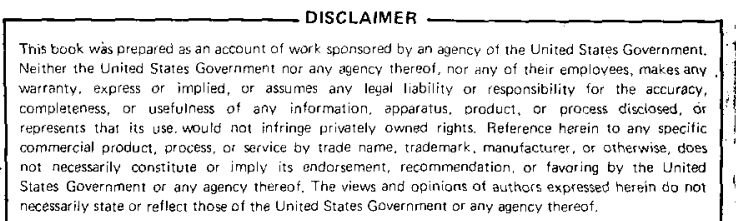

UNITED STATES DEPARTMENT OF ENERGY

This document is PUBLICLY RELEASABLE Lava O Or illiame Authorizing Official 


\section{DISCLAIMER}

This report was prepared as an account of work sponsored by an agency of the United States Government. Neither the United States Government nor any agency Thereof, nor any of their employees, makes any warranty, express or implied, or assumes any legal liability or responsibility for the accuracy, completeness, or usefulness of any information, apparatus, product, or process disclosed, or represents that its use would not infringe privately owned rights. Reference herein to any specific commercial product, process, or service by trade name, trademark, manufacturer, or otherwise does not necessarily constitute or imply its endorsement, recommendation, or favoring by the United States Government or any agency thereof. The views and opinions of authors expressed herein do not necessarily state or reflect those of the United States Government or any agency thereof. 


\section{DISCLAIMER}

Portions of this document may be illegible in electronic image products. Images are produced from the best available original document. 


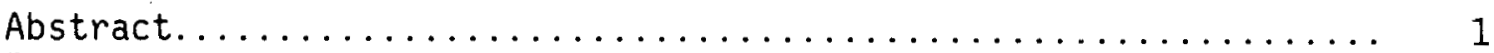

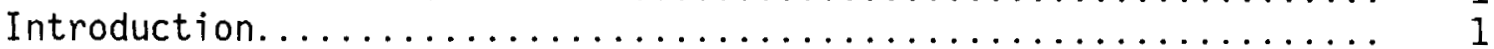

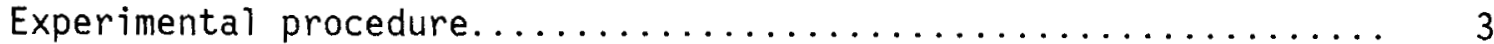

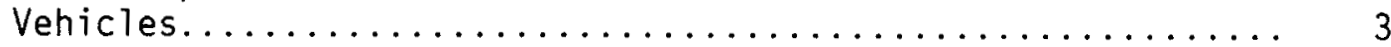

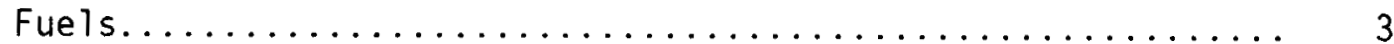

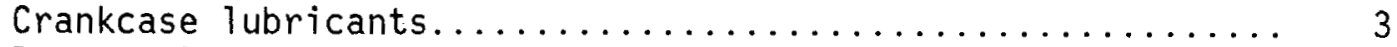

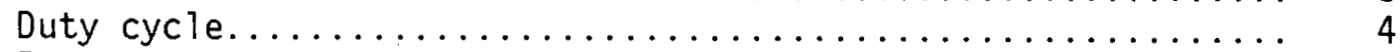

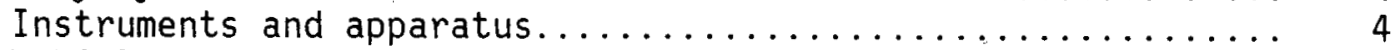

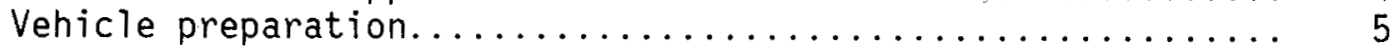

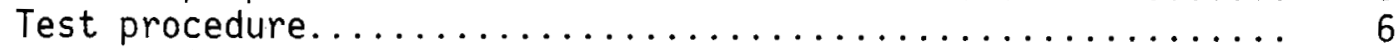

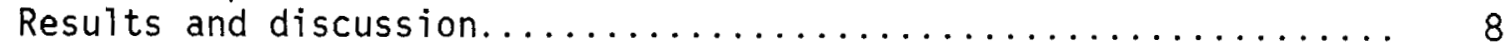

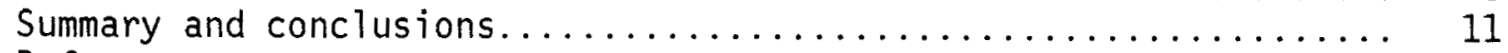

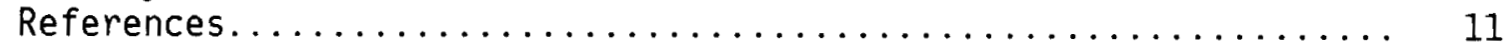

\section{ILLUSTRATIONS}

1. Test sequence............................. 7

2. Variation of base $0 i 1$ temperature over the FTP and HFET...... 10

\section{TABLES}

1. Lubricants' properties......................... 4

2. Percent improvement in combined fuel economy-candidate oils versus base $0 i 1 \ldots \ldots \ldots \ldots \ldots \ldots \ldots \ldots \ldots$

3. Carry-over characteristics of the candidate oils and oil supplements. 


\title{
DESIGN AND TESTING OF A PROCEDURE FOR \\ EVALUATING FUEL-EFFICIENT CRANKCASE LUBRICANTS
}

\author{
by
}

Ted M. Naman ${ }^{1}$

U.S. Department of Energy

Bartlesville Energy Technology Center

Bartlesville, Oklahoma

\begin{abstract}
Experiments were conducted at the U.S. Department of Energy's Bartlesville (OKla.) Energy Technology Center to design and evaluate a procedure for evaluating the fuel efficiency characteristics of crankcase lubricants using the driving cycles of the 1975 Federal Test Procedure and the High way Fuel Economy Test. Most of the test protocol was based on guidelines proposed by the American Society for Testing and Materials $(1)^{2}$.

Three crankcase lubricants and five oil supplements, as well as a baseline lubricant, were used in eight 1980 model-year vehicles of identical make. The vehicles were operated at $75^{\circ} \mathrm{F}\left(24^{\circ} \mathrm{C}\right)$ in closely controlled chassis dynamometer tests designed to detect small changes in fuel efficiency.

Results from these tests showed measurable increases in fuel economy of 0 to 6 percent with the test lubricants when compared to a common SAE 30 grade oil. These results are not definitive because of lack of quantification of mileage accumulation effects. The test protocol did reduce measurement variability greatly; this procedure can be applied to evaluation of fuel-efficient oils using larger test fleets.

A good potential exists for improving the fuel economy of the U.S. automotive fleet. Because of the large quantities of petroleum consumed in the automotive sector, this potential savings translates into conserving a very significant quantity of petroleum.
\end{abstract}

\section{INTRODUCTION}

The rising cost of gasoline and the increased demand for fuelefficient automobiles have led to new trends and developments in the automotive industry which, since 1974, have resulted in a 55 percent increase in fuel economy or a saving of 500 milition barrels of oil (2). These trends and developments include: (a) weight reduction by downsizing and increased use of plastics and light-weight metals; (b) reduced aerodynamic

\footnotetext{
1 Mechanical engineer.

2Underlined numbers in parentheses refer to references 1 isted at the end of this report.
} 
drag and tire rolling resistance; (c) better fuel management by increased use of electronic control systems; and (d) improved power train efficiency via energy-conserving lubricants.

The use of energy-conserving lubricants is especially appealing because it can be easily applied to the existing car population and, therefore, can have an immediate impact on the nation's transportation energy demands. If a fuel economy increase of 5 percent for the entire existing fleet could be achieved, approximately 100 million barrels of fuel would be saved annualiy.

Several engine oils, containing either soluble friction modifiers or solid materials present as colloidal suspensions, and oil supplements containing primarily polytetrafluoroethylene, have recently become commercially available. The manufacturers claim reduced engine friction and increased fuel economy when these products are used in passenger cars and trucks. The claims for fuel economy benefits range from moderate ( 2 to 5 percent) to extremely high (20 to 25 percent). A reasonable upper limit for fuel economy gain by minimizing boundary friction is about 7 percent (3). By minimizing boundary and hydrodynamic friction, an estimated 10 percent increase in fuel economy is possible.

Synthetic oils have been commercially available, but the major claims emphasize extended drain intervals, better performance, and improved fuel economy when compared to mineral oils under extreme temperature conditions (4). However, a low viscosity synthetic lubricant has shown potential for improved fuel economy under various driving cycles ( $\underline{5})$.

It is recognized industry-wide that developing a test procedure that can reliably and reproduciby detect small differences in fuel efficiency via crankcase lubricants is extremely difficult. Furthermore, reproducing a test within a narrow tolerance band is even more difficult because of the many variables that can affect fuel economy measurement, expecially if tests are conducted on the road using volumetric or gravimetric fuel consumption measuring systems. Some of these variables are wind direction and speed; ambient temperature; barometric pressure; relative humidity; vehicle curb-weight changes as related to the number of passengers and refueling; tire rolling resistance as related to road pavement changes; fuel volatility and specific gravity; odometer error; using the same driver in all fuel economy tests; maintaining the same throttle opening on a given route; and, if the vechicle is equipped with a manual transmission, shifting gears at the correct engine speeds; and, a very important factor, subconsciously changing driving habits to expect an increase in fuel economy.

Conducting tests on a climate-controlled chassis dynamometer eliminates several of these variables but still presents a problem of reproducibility unless extreme care is exercised in preparing the test vehicle and following certain practices. 
To address the questions considered above, the Department of Energy's Bartlesville Energy Technology Center (BETC) designed and conducted a series of experiments with several vehicles and commercially available lubricants. The specific purpose of this work was to provide data that could prove to be useful in answering several questions:

1. Can a test protocol be applied to testing of vehicles for fuel economy such that variability of measurements is reduced to an acceptable level? This is a necessary condition for results to be considered statistically significant.

2. What is the range of expected fuel economy increase? Can a 5 percent increase (considered to be very significant) be realized?

The program was not designed to address such broader issues as:

1. Can the results be extrapolated to the U.S. passenger car fleet?

2. What is the fleet size requirement for the test results to be considered statistically significant?

\section{EXPERIMENTAL PROCEDURE}

\section{Vehicles}

Eight 1980 model-year American-made front-wheel-drive (FWD) vehicles were used in this study. The vehicles were equipped with 2.5-1iter, 4-cylinder engines, automatic transmissions, air-conditioning, power steering, and power brakes. They were leased from a local rental agency with 6,000 to 10,000 miles recorded on the odometers; therefore, it was assumed that no mileage accumulation was required for break-in.

\section{Fuels}

Indolene fuel was used in the entire program, and its specifications conformed to the Code of Federal Regulations ( $\underline{6})$.

\section{Crankcase Lubricants}

Table 1 describes the properties of the following commercial lubricants:

1. An SAE 30 grade mineral, API service SE/CC (base lubricant);

2. An SAE 5W20 synthetic, API service SE/CC;

3. An SAE 10 W40 mineral with graphite in colloidal suspension, API service $\mathrm{SE} / \mathrm{CC}$; 
4. An SAE 10 W40 mineral with a soluble friction modifier, API service SE;

5. Three oil supplements containing primarily polytetrafluoroethylene and using a lubricant as a carrier; and

6. Two oil supplements containing primarily polytetrafluoroethylene and using a solvent as a carrier.

TABLE 1. - Lubricants' properties

\begin{tabular}{|c|c|c|c|c|c|c|c|c|c|}
\hline & $\begin{array}{c}\text { SAE } 30 \\
\text { Base } \\
\end{array}$ & $\begin{array}{r}10 W 40 \\
F E 0^{1} \\
\end{array}$ & $\begin{array}{r}10 W 40 \\
F^{2} O^{2} \\
\end{array}$ & $\begin{array}{l}5 \mathrm{~W} 20 \\
\mathrm{FEO}^{3} \\
\end{array}$ & $\begin{array}{c}0 S^{4} \\
\mathrm{~A}\end{array}$ & $\begin{array}{c}0 S^{4} \\
B\end{array}$ & $\begin{array}{c}0 S^{4} \\
C\end{array}$ & $\begin{array}{c}S^{5} \\
D\end{array}$ & $\begin{array}{c}0 S^{5} \\
E\end{array}$ \\
\hline Flash point, ${ }^{\circ} \mathrm{F}$ & 405 & 420 & 400 & 395 & - & - & - & - & - \\
\hline Kinematic viscosity, CS: & & & & & & & & & \\
\hline $100^{\circ} \mathrm{F} \ldots \ldots \ldots \ldots \ldots \ldots$ & 109.8 & 85.00 & 112.46 & 40.43 & - & - & - & - & 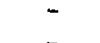 \\
\hline $\begin{array}{l}2 l 0 \text {...................... } \\
\text { Sulfated ash pct mass. }\end{array}$ & $\begin{array}{r}12.14 \\
0.78\end{array}$ & 15.16 & $\begin{array}{l}15.15 \\
1.18\end{array}$ & 6.87 & - & - & - & - & \\
\hline $\begin{array}{l}\text { Elemental analysis, } \\
\text { pct mass: }\end{array}$ & 0.18 & 0.13 & 1.18 & 1.05 & & & & & \\
\hline Ba............ & 0.005 & 0.007 & 0.121 & 0.002 & 0.004 & 0.034 & 0.002 & 0.005 & 0.017 \\
\hline Ca. . & 0.228 & 0.296 & 0.002 & 0.227 & 0.004 & 0.069 & 0.000 & 0.005 & 0.998 \\
\hline & 0.109 & 0.011 & 0.073 & 0.004 & 0.003 & 0.019 & 0.001 & 0.002 & 0.009 \\
\hline $\mathrm{Zr}$ & 0.191 & 0.187 & 0.154 & 0.169 & 0.210 & 0.056 & 0.007 & 0.018 & 0.042 \\
\hline P. & 0.159 & 0.156 & 0.108 & 0.093 & 0.259 & 0.067 & 0.001 & 0.094 & 0.005 \\
\hline API service & $\mathrm{SE} / \mathrm{CC}$ & $\mathrm{SE} / \mathrm{CC}$ & SE & $\mathrm{SE} / \mathrm{CC}$ & & & & & \\
\hline
\end{tabular}

$1=$ Fuel-efficient oil with graphite.

2 = Fuel-efficient oil with a soluble friction modifier.

3 = Fuel-efficient oil, synthetic.

$4=0 i l$ supplement, lubricant base.

$5=0 i l$ supplement, solvent base.

- = No measurement.

\section{Duty Cycle}

The 1975 Federal Test Procedure (FTP) and the Highway Fuel Economy Test (HFET) were used in this study. The tests conformed to the code of Federal Regulations ( 6 ) with the exception of certain modifications of the test vehicles made to minimize errors associated with fuel economy measurement. These modifications will be discussed in detail in a separate section of this report.

\section{Instruments and Apparatus}

The tests were conducted at $75^{\circ} \mathrm{F}\left(24^{\circ} \mathrm{C}\right)$ on a climate-controlled chassis dynamometer. Care was exercised to maintain $75^{\circ} \mathrm{F}\left(24^{\circ} \mathrm{C}\right) \pm$ $2^{\circ} \mathrm{F}\left(0.9^{\circ} \mathrm{C}\right)$ and 50 percent \pm 5 percent relative humidity, rather than following the recommended broader range of $68^{\circ}-86^{\circ} \mathrm{F}\left(20^{\circ}-30^{\circ} \mathrm{C}\right)(\underline{5})$. The exhaust emissions were collected using the "bag sampling" technique, and fuel economy was calculated using the carbon balance method. In addition, real-time information on emissions and fuel economy was obtained by use of 
an on-line data acquisition system which provided continuous readouts and checks on the bag analyses. Duplicate tests were conducted on each lubricant with each vehicle.

\section{Vehicle Preparation}

It is a followed practice at BETC, when a new test vehicle is acquired, to accumulate a minimum of 4,000 miles of urban/highway driving prior to conducting tests. The objective is to stabilize exhaust emissions and fuel economy. Beyond 4,000 miles, some fluctuations in fuel economy are likely, but they are minimal when compared to fluctuations during the first 4,000 miles. Several of the vehicles used in this project accumulated about 5,000 miles over the period of testing; this could be expected to have some effect on fuel economy. Based on historical information from the Environmental Protection Agency certification and durability tests (7), the increase in fleet average fuel economy over an equivalent 5,000-mile accumulation is approximately 1 percent. While this is a relatively small increase, in many cases it could be a significant portion of the apparent fuel economy gains attributed to the lubricants.

In order to minimize errors associated with fuel economy measurement, the following precautionary measures were taken with each vehicle:

- The engine was double-flushed with the base oil using a blank oil filter, the crankcase was filled with the fresh base oil, and a new filter was installed.

- The vehicle underwent a major tune-up. This included replacement of spark plugs, air filter, fuel filter, PCV valve, and an oscilloscope-check of the ignition system.

- The following were checked: anti-freeze solution in the radiator for proper specific gravity, transaxle and power steering fluids, emission control systems, engine compression, distributor vacuum and mechanical advance systems, and intake manifold vacuum at curb idle.

- The curb idle, fast idle, and spark timing were adjusted to specifications.

- Thermocouples were installed in the water jacket and the oil drain plug, and temperatures were measured once every minute throughout the test and averaged over the entire FTP and HFET.

- The alternator was disconnected from the battery without removing the belt, and a battery charger was connected to the battery and maintained at the same charging rate during all tests.

- The air conditioning compressor clutch was disengaged from the compressor without removing the belt. 
- The fuel tank was filled to one-half its volume, thus providing uniform gross vehicle weight.

- The driving tires were inflated to $45 \mathrm{psi}(310 \mathrm{KPa})$.

- The vent line from the fuel tank to the charcoal canister was disconnected from the canister.

- Since the vehicles were FWD, they were anchored in the same position to prevent side movement.

- The same driver was used in the majority of the tests.

- In most cases the vehicles were conditioned on the chassis dynamometer at the test ambient temperature; however, due to the limitation of the test facility, the vehicles were occasionally conditioned on the road at $55 \mathrm{mph}$ for 15 to $20 \mathrm{miles}$ with the vent line from the fuel tank to the charcoal canister disconnected.

- The vehicles were soaked for a minimum of 12 hours and for a maximum of 16 hours at the test ambient temperature with the hoods open.

- The chassis dynamometer was warmed up for 30 minutes with a control car at inertia loads and horsepower settings prescribed for the test vehicles.

In addition to the above measures, chassis dynamometer calibrations were performed on a regular basis to detect and correct any drift in the instrumentation.

\section{Test Procedure}

The objective was to evaluate one lubricant per vehicle under closely controlled chassis dynamometer conditions, with emphasis placed on the preparation of the vehicle for testing and on the factors mentioned previously which can affect fuel economy measurement, thereby minimizing the source of error in test repeatability.

One factor that can influence the baseline fuel economy in this test procedure is the presence of a carry-over-type oil or oil supplement in the crankcase prior to acquiring lease vehicles. For the eight vehicles tested, no carry-over-type oils were present in the crankcase. Most of the vehicles had the factory-fill lubricant prior to leasing; for the others, a nonfuel-efficient 10 w40 oil had been added to the crankcase at the manufacturer's recommended drain intervat. A schematic diagram of the test sequence is shown in figure 1 . 

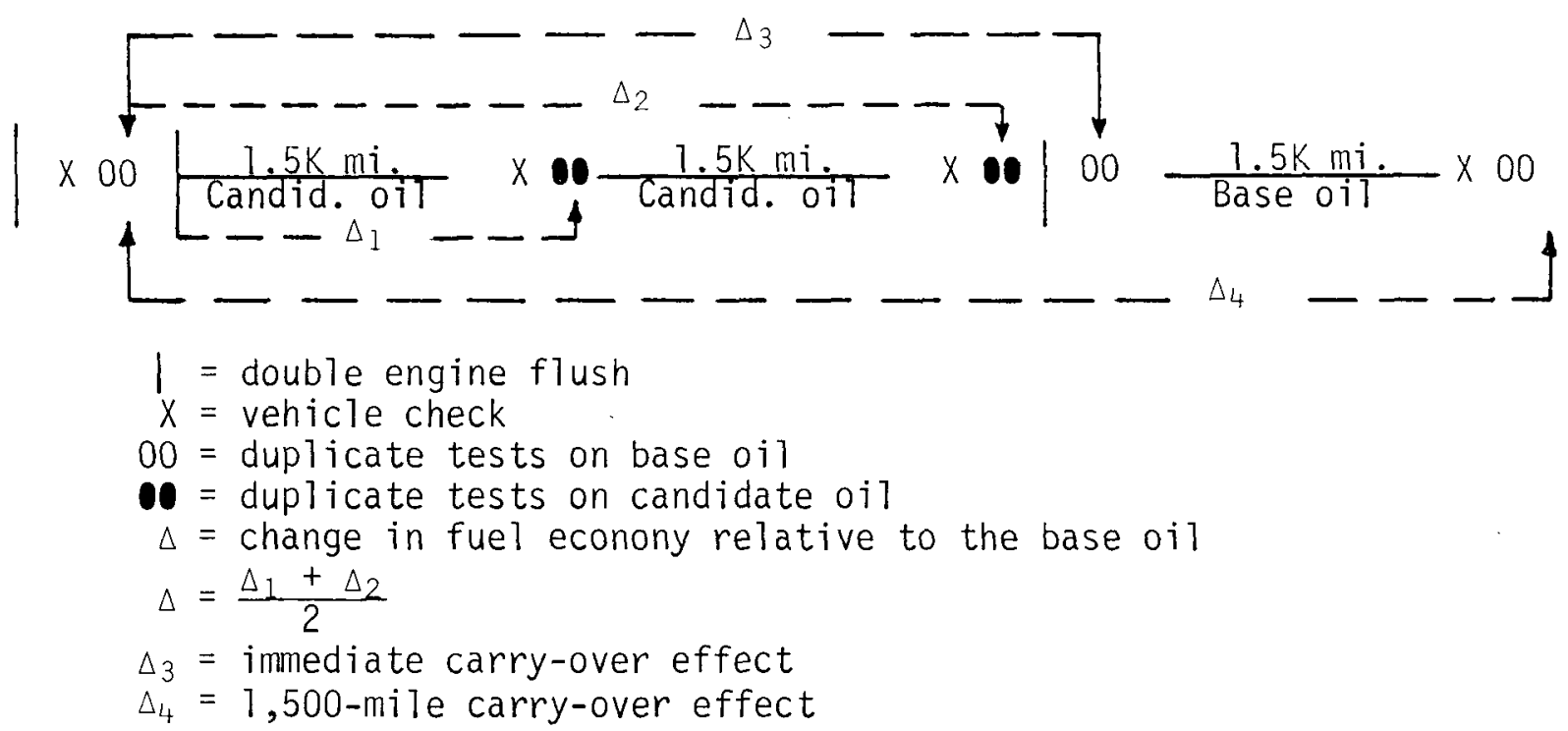

\section{FIGURE 1. - Test sequence.}

Following the tests on the base oil, the engine was double-flushed with the candidate $0 i 1$, and the vehicle accumulated 1,500 miles on the candidate $0 i l$ on the road. Based on our experience with vehicle testing, 1,500 miles was sufficient to detect initial changes in fuel economy with crankcase lubricants. Following duplicate tests at 1,500 miles, an additional 1,500 miles was accumulated to determine if further fuel economy benefits could be detected. Following the 3,000-mile test on the candidate $0 i l$, the engine was double-flushed with the base oil, and duplicate tests were conducted on the base oil. The idea here was to determine whether or not the candidate oil exhibited carry-over characteristics following the oil change. The vehicle then accumulated 1,500 miles on the base oil, and duplicate tests were then conducted to determine if further carry-over effects could be detected.

For the purposes of this report, the fuel economy for the candidate oil was defined as the average of the measurements obtained at the 1,500and 3,000-mile accumulations. The change in fuel economy was defined as this average compared to the baseline value. Carry-over effects were also referenced to the baseline value.

For the candidate oil supplements, 1,500 miles of driving--with the exception of oil supplement A (see table 1), which underwent 3,000 miles of conditioning as recommended by the manufacturer--was sufficient to show measurable changes in fuel economy. Based on our experience with evaluation of various oil supplements, the effects on fuel economy were generally observed as early as 500 miles of driving, and these effects could still be pronounced for several thousand miles. Therefore, it is possible that 1,500 miles may not be enough to show the full benefit of the oil supplement. The change in fuel economy with the candidate oil supplements was that at 1,500 miles compared to the fuel economy with the base $0 i 1$. 
The vehicle check prior to each set of duplicate tests was an important part of the overall test procedure because it detected malfunctions in vehicle operation prior to conducting the test. For the eight vehicles tested, no malfunctions were detected at any time; however, if the idle speed had changed with any of the candidate oils due a reduction or an increase in engine friction (this was usually accompanied by a change in intake manifold vacuum), then the idle speed was reset to original specifications as with the base oil. No other modifications were made to the engines throughout the entire test.

\section{RESULTS AND DISCUSSION}

Results of the tests of the eight crankcase oils and oil supplements indicate an increase in fuel economy of less than 1 percent to approximately 6 percent (table 2). The changes in fuel economy can generally be attributed to:

(1) measurement errors,

(2) engine operating changes,

(3) mileage accumulation effects, and

(4) lubricant effects--viscosity, friction reduction.

TABLE 2. - Percent improvement in combined fuel economy

--Candidate oils versus base oil--

\begin{tabular}{|c|c|c|c|c|c|c|c|c|c|c|c|}
\hline \multirow{3}{*}{$\begin{array}{l}\text { - Test } \\
\text { vehicle }\end{array}$} & \multirow{3}{*}{$\begin{array}{c}\text { Candidate } \\
\text { oil }\end{array}$} & \multicolumn{9}{|c|}{ Fuel ecomomy, mpg } & \multirow{3}{*}{$\begin{array}{l}\text { Change } \\
\text { Avg pct }\end{array}$} \\
\hline & & \multicolumn{3}{|c|}{ Base oil } & \multicolumn{3}{|c|}{$\begin{array}{c}\text { T,500-mile } \\
\text { Candidate oil }\end{array}$} & \multicolumn{3}{|c|}{$\begin{array}{c}\text { 3,000-mile } \\
\text { Candidate oil }\end{array}$} & \\
\hline & & Avg & Std dev. & C.0.V. & Avg & Std dev. & C. $0 . \mathrm{V}$ & Avg & Std dev. & C. $0 . \mathrm{V}$. & \\
\hline 1 & $10 W 40$ FEO $^{1}$ & 24.35 & 0.19 & 0.8 & 25.35 & 0.00 & 0.0 & 26.45 & 0.23 & 0.9 & +6.4 \\
\hline 7 & $10 W 40 \mathrm{FEO}^{2}$ & 27.63 & 0.18 & 0.7 & 27.55 & 0.30 & 1.1 & 27.93 & 0.38 & 1.4 & +0.4 \\
\hline 3 & $5 W 20 \mathrm{FEO}^{3}$ & 25.85 & 0.28 & 1.1 & 26.71 & 0.06 & 0.2 & 27.38 & 0.06 & 0.2 & +4.6 \\
\hline 4 & $O S^{4}-A$ & 22.43 & 0.06 & 0.3 & - & - & - & 23.86 & 0.13 & 0.5 & +6.4 \\
\hline 5 & $O S^{4}-B$ & 23.68 & 0.33 & 1.4 & 24.26 & 0.25 & 1.1 & - & - & - & +2.4 \\
\hline 6 & $05^{4}-C$ & 23.52 & 0.37 & 1.3 & 24.31 & 0.16 & 0.7 & - & - & - & +3.4 \\
\hline 7 & $0 S^{5}-0$ & 26.70 & 0.21 & 0.8 & 27.20 & 0.37 & 1.4 & - & - & - & +7.9 \\
\hline 8 & $O S^{5}-E$ & 24.24 & 0.08 & 0.3 & 24.29 & 0.06 & 0.3 & - & - & - & +0.2 \\
\hline
\end{tabular}

$1=$ Fuel-efficient oil with graphite.

2 = Fuel-efficient oil with a soluble friction modifier .

3 = Fuel-efficient oil, synthetic.

$4=0 i 1$ supplement, lubricant base.

$5=0 i 1$ supplement, solvent base.

- = No measurement.

c.o.v. = Coefficient of variation (std dev./avg), pct. 
The test results indicate good repeatability; the average value for the coefficient of variation (COV) was about 1 percent. At this laboratory, in previously conducted emissions and fuel economy tests in which a less stringent protocol was applied, the COV for fuel economy measurements was about 3 percent. Thus it appears that at least some of the additions to the test procedure for this work contributed to improving the measurement reliability.

Having attained this improvement in measurement repeatability, however, does not allow attaching statistical significance to small improvements in fuel economy based on tests with one vehicle. Given a 1 percent COV, the results from paired tests must show a minimum increase of 3 percent in order to have statistical significance at a 95 percent level of confidence. If the lubricant test results show a 1 percent increase, the COV must be held to about 0.1 percent for a statistically valid conclusion that the effect is real. This indicates the need for larger fleets and increased number of tests for more definitive evaluation of fuel economy effects of lubricants.

Changes in engine operation can occur as a consequence of degradation of fuel metering system, ignition system, and emission control components. Any significant changes in these systems should result in altered emissions characteristics. Emissions measurements were included in all tests conducted in this work. There was no evidence of any significant shifts in emission levels. An assessment of these results yields the conclusion there was little likelihood of any changes in engine adjustment or operation of a sufficient degree to have significant effect on fuel economy.

The effect of mileage accumulation on fuel economy is not known for the vehicle model used in this work. As noted previously, the fleet average fuel economy increased by about 1 percent over a 5,000-mile accumulation. In the analysis of the historical data, no statistical justification was found for inclusion of model year, manufacturer, and inertia weight as independent variables. Therefore, although these vehicles might not behave exactly as the fleet average, there is no historical evidence to predict that they will be markedly different.

A rough measure of the mileage accumulation effect might be obtained from results of tests conducted after reintroduction of the base oil into the crankcase, if there are no carry-over effects. Apparent carry-over effects (table 3) cover a broad range--from slightly negative to about 8 percent. Of the seven oils tested, the 5 W20 synthetic would be least likely to have any significant carry-over effects. Thus, the 2.9 percent increase might be an indication of the mileage accumulation effect over the 5,000-mile test period. This value is in fair agreement with that recently found by other researchers for a small fleet of recent model-year vehicles (요). 
TABLE 3. - Carry-over characteristics of the candidate oils and oil supplements

\begin{tabular}{|c|c|c|c|c|c|c|c|c|}
\hline \multirow{3}{*}{$\begin{array}{c}\text { Test } \\
\text { vehicle }\end{array}$} & \multirow{3}{*}{$\begin{array}{c}\text { Candidate } \\
0 i 1\end{array}$} & \multicolumn{6}{|c|}{ Base oil fuel economy, mpg } & \multirow{3}{*}{$\begin{array}{l}\text { Average } \\
\text { carry-over } \\
\text { effect, pct }\end{array}$} \\
\hline & & \multicolumn{2}{|c|}{$\begin{array}{c}\text { Before } \\
\text { candidate oil }\end{array}$} & \multicolumn{2}{|c|}{$\begin{array}{c}\text { After } \\
\text { candidate oil } \\
\end{array}$} & \multicolumn{2}{|c|}{$\begin{array}{c}\text { After } \\
1,500 \text { miles }\end{array}$} & \\
\hline & & Avg & Std dev & Avg & Std dev. & Avg & Std dev. & \\
\hline 1 & IOW40 FEO ${ }^{1}$ & 24.35 & 0.19 & 26.67 & 0.15 & 26.10 & 0.13 & +8.4 \\
\hline 3 & $5 \mathrm{~W} 20 \mathrm{FEO}^{2}$ & 25.85 & 0.28 & 26.75 & 0.27 & 26.43 & 0.43 & +2.9 \\
\hline 4 & $O S^{3}-A$ & 22.43 & 0.06 & 23.22 & 0.27 & 23.20 & 0.07 & +3.5 \\
\hline 5 & $O S^{3}-B$ & 23.68 & 0.33 & 24.98 & 0.42 & 25.09 & 0.34 & +5.7 \\
\hline 6 & $O S^{3}-C$ & 23.52 & 0.31 & 23.67 & 0.33 & 23.61 & 0.13 & +0.5 \\
\hline 7 & $O S^{4}-D$ & 26.70 & 0.21 & 27.28 & 0.23 & 27.30 & 0.16 & +2.2 \\
\hline 8 & $O S^{4}-E$ & 24.24 & 0.08 & 24.27 & 0.01 & 23.87 & 0.06 & -0.7 \\
\hline
\end{tabular}

$1=$ Fuel-efficient oil with graphite.

2 = Fuel-efficient $0 i 1$, synthetic .

$3=0 i l$ supplement, lubricant base.

$4=0 i l$ supplement, solvent base.

Lubricant effects on fuel economy are influenced by viscosity and boundary friction. Gains in fuel economy can be achieved by using oils with lower viscosity at low or high temperature, or at both temperature ranges. The temperature of the crankcase oil was monitored over each test (figure 2). Note that the $0 i 1$ temperature was below $100^{\circ} \mathrm{F}\left(38^{\circ} \mathrm{C}\right)$ for an appreciable period (roughly five minutes). Hydrodynamic friction losses are greater at low temperature (high viscosity) conditions. Some increase in fuel economy can be achieved by substituting a $5 \mathrm{~W}$ oil for an SAE 30 oil, as is indicated by results for the $5 W 20$ oil (table 2). Much smaller effects are generally found at the higher operating temperatures where the differences in viscosities between the oils is much less than at low temperatures.

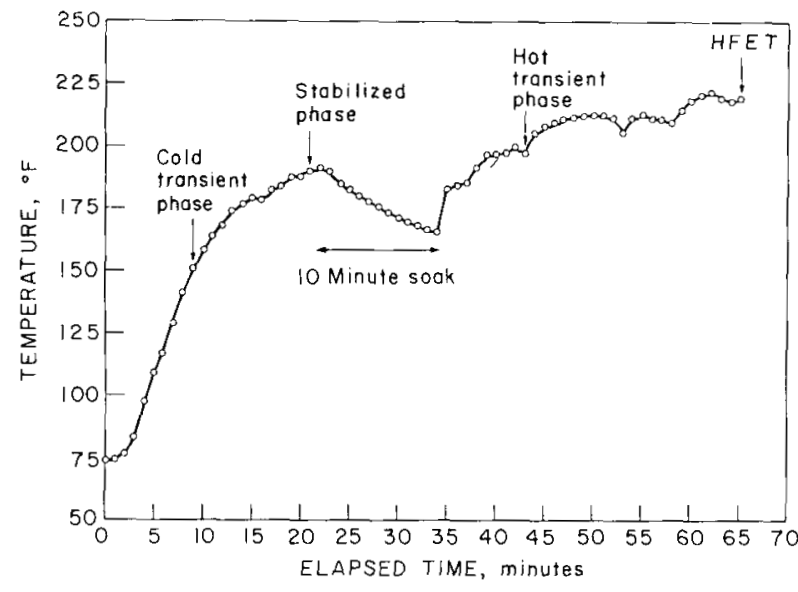

FIGURE 2. - Variation of base oil temperature over the FTP and hFET.

Reduction of friction through friction modifiers is the mechanism for increased fuel economy for seven of the crankcase oils and supplements used in this work. Estimates of improvements in fuel economy by reducing boundary friction are imprecise, because this was not measured directly. It is the "residual" fuel economy gain after accounting for measurement 
error, mileage accumulation effect, and viscosity effects. Because of the uncertainty in the mileage accumulation effect (probably in the range of 0.5 percent to 2.5 percent for vehicles in this work), the estimate for fuel economy gain attributable to friction-modified oils and oil supplements covers the range from essentially zero to about 6 percent.

\section{SUMMARY AND CONCLUSIONS}

An experimental procedure for evaluating the fuel-efficiency characteristics of crankcase lubricants was designed and tested. Results of this work show:

1. The test protocol yielded good measurement repeatability, as evidenced by only small variations in results of duplicate tests.

2. The effect of mileage accumulation on fuel economy must be quantified for the vehicle models used in testing fuel-efficient oils. If this is not quantified, the error in estimates of the effectiveness of the fuel-efficient oils can be significant.

3. Although this test procedure yielded highly repeatable results, a larger test fleet is required for statistically significant results.

4. The size of the test fleet required for extrapolation of test results to the U.S. automotive fleet cannot be estimated from this work. However, the fleet size must satisfy item 3 , above.

5. Results of tests with eight crankcase oils and oil supplements showed fuel economy increases of up to 6 percent. Although this cannot be extrapolated to the U.S. automotive fleet, it does indicate a potential for conserving a substantial quantity of petroleum through use of fuel-efficienct oils.

\section{REFERENCES}

1. American Society for Testing and Materials (ASTM) Development Task Force, "Fuel Saving Engine 0il Test Procedure," a tentative draft, March 5, 1980.

2. Petroleum Refining and Petrochemicals Literature, July 28, 1980, Abstract No. 27-4575, p. 7.

3. Marshal1, H. P., "Maximum and Probable Fuel Economy of Automobiles." Presented at the Congress and Exposition Meeting, Society of Automotive Engineers, Detroit, Michigan, February 25-29, 1980, SAE Paper $800213,12 \mathrm{pp}$.

4. Naman, T. M., "Automotive Fuel Economy-Potential Improvement Through Selected Engine and Gear Lubricants." Presented at the Congress and Exposition Meeting; Society of Automotive Engineers, Detroit, Michigan, February 25-29, 1980, SAE Paper 800438, 23 pp. 
5. Lohuis, J. R., J. A. Murphy, and T. W. Rogers, "The Performance of Fuel-Saving Engine 0ils." Presented at the Congress and Exposition Meeting, Society of Automotive Engineers, Detroit, Michigan, February 25-29, 1980, SAE Paper 800436, 20 pp.

6. U.S. Code of Federal Regulations. Title 40--Protection of Environment; Chapter I--Environmental Protection Agency; Subchapter C--Air Programs; Part 86--Control of Air Pollution from New Motor Vehicles and New Motor Vehicle Engines; Subpart B--Emissions Regulations for 1977 and Later Model Year New Light-Duty Vehicles and Light-Duty Trucks, Test Procedures; Sections 86.105-78 through 86.144-78. Revised July 1, 1978.

7. Murrel1, J. D., "Light-Duty Automotive Fuel Economy--Trends Through 1979." Presented at the Congress and Exposition Meeting, Society of Automotive Engineers, Detroit, Michigan, February 26-March 2, 1979 , SAE Paper 790225, $32 \mathrm{pp}$.

8. Deane, D. C., H. Shaub, and W. E. Waddy, "Testing of 0ils Having Carryover Fuel Economy Effects." Presented at the Congress and Exposition Meeting, Society of Automotive Engineers, Detroit, Michigan, February 23-27, 1981, SAE Paper 810317, $16 \mathrm{pp}$. 